\title{
Investigation of the response time of the equatorial ionosphere in context of the equatorial electrojet and equatorial ionization anomaly
}

\author{
L. Jose ${ }^{1}$, S. Ravindran ${ }^{1}$, C. Vineeth ${ }^{1}$, T. K. Pant ${ }^{1}$, and S. Alex ${ }^{2}$ \\ ${ }^{1}$ Space Physics Laboratory, Vikram Sarabhai Space Centre, Trivandrum, India \\ ${ }^{2}$ Indian Institute of Geomagnetism, Navi Mumbai, India
}

Received: 29 November 2010 - Revised: 22 June 2011 - Accepted: 4 July 2011 - Published: 19 July 2011

\begin{abstract}
Equatorial Electrojet (EEJ) and Equatorial Ionization Anomaly (EIA) are two large-scale processes in the equatorial/low latitude ionosphere, driven primarily by the eastward electric field during daytime. In the present paper we investigate the correlation between the Integrated EEJ strength (IEEJ) and the EIA parameters like the total electron content at the northern crest, location of crest in Magnetic latitude and strength of the EIA for the Indian sector. A good correlation has been observed between the IEEJ and EIA when a time delay is introduced between IEEJ and EIA parameters. This time delay is regarded as the response time of equatorial ionosphere in context of the evolution of EIA vis-à-vis EEJ. Further, a seasonal variation in the time delay has been observed, which is believed to be due to changes in thermospheric wind. Using the response time and the linear relationship obtained, the possibility of near-real time prediction of EIA parameters has been attempted and found that the prediction holds well during the geomagnetically quiet periods. The paper discusses these aspects in detail.
\end{abstract}

Keywords. Ionosphere (Electric fields and currents; Equatorial ionosphere)

\section{Introduction}

Equatorial and low latitude ionosphere has many unique features like Equatorial Electrojet (EEJ), Equatorial Ionization Anomaly (EIA) and is more likely to have Equatorial spread $\mathrm{F}$ (ESF)/scintillations and other irregularities. These phenomena are the manifestation of the unique electrodynamics in this region. The EEJ refers to an intense band of eastward current centered at dip equator flowing in the height range of 90-130 km, during daytime (Forbes, 1981; Richmond, 1989;

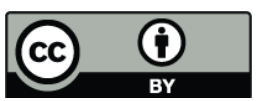

Correspondence to: L. Jose (lijojosek@gmail.com)
Reddy, 1989). In simple thin shell model, generation of EEJ can be explained as follows. The mutually perpendicular nature of the primary electric field (generated due to the tidal wind) and magnetic field in the equatorial E-region give rise to a vertical polarization electric field. This in turn being perpendicular to the northward horizontal magnetic field gives rise to an enhanced current in the E-region, called the EEJ.

The EIA was discovered by Appleton (1946) and later explained by Mitra (1946) and Martyn (1947) in terms of "fountain effect". The upward plasma drift associated with the EIA is produced by the F-region electric field, which is mapped from the E-region along the magnetic field lines during daytime. Because of the perpendicular nature of the electric and magnetic fields the plasma is lifted upward by $\boldsymbol{E} \times \boldsymbol{B}$ drift. At higher altitudes, plasma diffuses downward along the geomagnetic field lines on either sides of the dip equator by the action of gravitational and pressure gradient forces. This creates a double hump structure in the horizontal distribution of the electron density over equatorial/low latitude ionosphere, known as the EIA. Apart from this, the generation, evolution and latitudinal extent of the EIA is strongly depend on the variability of the zonal electric field, prevailing space weather conditions, high-latitude low-latitude coupling, season and solar activity (Anderson, 1973a, b; Rastogi, 1959; Abdu et al., 1990; Sastri, 1990). From the above descriptions it is clear that both the EEJ and EIA are driven primarily by the same eastward electric field. Therefore it is quite natural to expect a correlation between these two. However, it should be noted that the EEJ strength is only an indirect measure of electric field as it is also determined by conductivities, which is a function of solar flux. In the absence of direct electric field measurements, this can be used as a proxy for the electric field and many studies have already been conducted in this direction.

Dunford (1967) was the first to report significant correlation between the strength of EIA and daily range of horizontal magnetic field at the equatorial station using the topside

Published by Copernicus Publications on behalf of the European Geosciences Union. 
sounder data. The strength of the EIA was defined as the depth of the EIA, $D=\left(N_{\mathrm{p}}-N_{\mathrm{e}}\right) / N_{\mathrm{e}}$ multiplied by width $W=\mathrm{Lat}_{\mathrm{p}}-\mathrm{Lat}_{\mathrm{e}}$ of the anomaly. Where $N_{\mathrm{p}}$ and $N_{\mathrm{e}}$ are electron densities at the peak and magnetic equator respectively and $W$ is the location of crest (Lat $)$ with respect to magnetic equator $\left(\mathrm{Lat}_{\mathrm{e}}\right)$. Later on, using ground-based ionograms, Rastogi and Rajaram (1971) reported that the midday bite out of $N m \mathrm{~F} 2$ at trough and afternoon peak of $N m \mathrm{~F} 2$ at crest are systematically enhanced in accordance with the horizontal geomagnetic field at the equatorial station. Rush and Richmond (1973) used $f o \mathrm{~F} 2$ data to study the correlation between midday EEJ values and EIA. They found maximum correlation for EIA parameters obtained between 14:00 and 16:00 LT and a lag of $2-3 \mathrm{~h}$ between the two. The correlation is found to be maximum during the equinoxes and minimum in June solstice. This was attributed to the strong electrodynamical control during equinoxial months. Deshpande et al. (1977) showed that crest development is strong during a strong EEJ day, weak during Counter Electrojet (CEJ) day and not at all developed during a geomagnetically disturbed day. They found a time delay of $\sim 2 \mathrm{~h}$ between the starting of CEJ and the near-end of the EIA. Raghavarao et al. (1978) have reported a correlation of $\sim 0.9$ between the electron density at $500 \mathrm{~km}$ altitude and the time integrated EEJ strength. Rastogi and Klobuchar (1990) observed a further increase in correlation between these two when mean EEJ strength between 07:00 and 14:00 LT is used.

The aforesaid studies confirmed that the development of EIA depends not only on the midday instantaneous values but also on the past history of EEJ variation. Using the Total Electron Content (TEC) data from ATS 6 geostationary satellite, Balan and Iyer (1983) have brought out the seasonal variation (summer, winter and equinox) of the EIA with respect to the EEJ strength. They found high correlation between the peak EIA strength and the peak value of horizontal field for all the seasons. They also reported a consistent time lag of 3-4 $\mathrm{h}$ between the maximum EIA and the EEJ current, which was regarded as the time required for the evolution of the EIA. Using the data from the Navy Navigation Satellite System (NNSS) and the ETS-2 satellite, Huang et al. (1989) have shown that the latitude of the EIA crest is more correlated to the EEJ strength than its magnitude. Similarly, a high correlation between the height of the peak F2 layer at the trough region and the EEJ strength has been reported from the Brazilian sector (Abdu et al., 1990). They found a response time of 2.5-4h between height of F2 peak over the equator and enhanced electron density at the EIA crest. The response time is suggested to be dependent on vertical drift velocity, height of the populated flux tube (longer time for higher flux tubes) and the intensity of the meridional winds.

The dependence of EIA on EEJ got further confirmation when using the Global Positioning System (GPS) TEC data of solar minimum period. The daily values of maximum EIA parameters were shown to be highly correlated with daily-integrated EEJ strength (Rao et al., 2006). Using the measurements from satellite based Planar Langmuir Probe (PLP), Stolle et al. (2008) have shown that the Crest to trough ratio of EIA responds to the variations of vertical drift values with a time delay of $\sim 1-2 \mathrm{~h}$ and EEJ strength $\sim 2-4 \mathrm{~h}$. On the whole, the time delay between EIA and EEJ appears to be $\sim 2-4 \mathrm{~h}$ on geomagnetically quiet days. Over the Indian region, most of these studies have been performed using ionograms or satellite data. In the present paper, we used GPS TEC data from a longitudinal network of stations in the Indian region for finding the response time of EEJ on EIA in the Indian sector. The advantage of using GPS data is that the TEC values are available round the clock and the exact response time could be found out. Most of the previous studies used instantaneous values of EEJ or integrated value for the whole day to find out the correlation. Here, instead of taking a single value, Integrated EEJ (IEEJ) strength is obtained at every $20 \mathrm{~min}$ from 07:00 LT onwards till the peak of the EEJ. This is correlated with EIA parameters averaged for every $20 \mathrm{~min}$ by introducing a time delay between the two. The time delay at which the maximum correlation obtained is considered to be the response time of the EIA. Using this, a near-real time prediction of EIA parameters have been attempted and found that the prediction holds well during all the days, which are geomagnetically quiet. This is believed to have great importance in space based navigation systems where the near-real time ionospheric predictions are required.

\section{Experimental data and method of analysis}

The GPS satellite system is one of the widely used tools for ionospheric studies. GPS uses two L-band signals L1 $(1.5754 \mathrm{GHz})$ and $\mathrm{L} 2(1.2276 \mathrm{GHz})$ for deriving Total Electron Content (TEC) along the signal path (Klobuchar, 1996). Since GPS satellites are available all the time, it is a very good tool for studying the time evolution EIA. As a part of GAGAN, (GPS Aided Geo Augmented Navigation) a combined project by Indian Space Research Organization (ISRO) and Airport Authority of India (AAI), a network of eighteen dual frequency GPS TEC monitoring stations have been setup over the Indian region. To study the day-to-day variability of EIA for the solar minimum epoch, a chain of six TEC stations along $77-78^{\circ} \mathrm{E}$ longitude [Trivandrum $\left(8.5^{\circ} \mathrm{N}\right.$, $77^{\circ} \mathrm{E}, 0.31^{\circ} \mathrm{S}$ mag. lat.), Bangalore $\left(12.5^{\circ} \mathrm{N}, 77.5^{\circ} \mathrm{E}, 3.6^{\circ} \mathrm{N}\right.$ mag. lat.), Hyderabad $\left(17^{\circ} \mathrm{N}, 78.5^{\circ} \mathrm{E}, 8.5^{\circ} \mathrm{N}\right.$ mag. lat.), Bhopal $\left(23^{\circ} \mathrm{N}, 77.5^{\circ} \mathrm{E}, 14.25^{\circ} \mathrm{N}\right.$ mag. lat), Delhi $\left(28.5^{\circ} \mathrm{N}\right.$, $77^{\circ} \mathrm{E}, 19.5^{\circ} \mathrm{N}$ mag. lat) and Shimla $\left(31^{\circ} \mathrm{N}, 77^{\circ} \mathrm{E}, 22^{\circ} \mathrm{N}\right.$ mag. lat)] are selected. While converting the measured slant TEC to vertical TEC, satellite elevation angle cut off of $60^{\circ}$ (to eliminate the errors due to large gradient changes in the equatorial and low latitude regions) and IPP (Ionospheric Pierce Point) altitude of $350 \mathrm{~km}$ are used.

The Magnetic field data from two stations, an equatorial station Tirunelveli $\left(8.7^{\circ} \mathrm{N}, 77.8^{\circ} \mathrm{E}, 0.17^{\circ} \mathrm{S}\right.$ dip lat. $)$ and 
an off equatorial station Alibag $\left(18.64^{\circ} \mathrm{N}, 72.87^{\circ} \mathrm{E}, 10.2^{\circ} \mathrm{N}\right.$ dip lat.) are used to estimate the EEJ strength. The EEJ strength is obtained after subtracting the night time mean value at each station and then finding the difference between two stations, i.e. $\Delta H_{\mathrm{TIR}}-\Delta H_{\mathrm{ALI}}$ (Rastogi and Klobuchar, 1990). It is well accepted that the EEJ strength can be used as a suitable proxy for the strength of the E-region electric field. It is also known that IEEJ is a much better parameter for correlating the evolution of EIA as the latter is formed due to the cumulative effect of the electric field (Rastogi and Klobuchar, 1990; Raghavarao et al., 1978). In order to eliminate the effects of geomagnetic disturbances, only quiet days with Ap values $<10$ are considered for the present study. Days corresponding to the recovery period are also omitted to avoid disturbance effect, if any. Therefore, in a month about 5 to 10 quiet days are available, which are being used to represent the seasonal variability. It is seen that, most of the days the signature of the EIA started appearing in GPS TEC at around 10:00 LT and therefore the EIA parameters are obtained after this time. The one minute TEC data from the above stations have been averaged for every $20 \mathrm{~min}$, interpolated and smoothed by taking a running mean, for a better representation of the evolution of EIA. It is assumed that the ionosphere does not change drastically within $20 \mathrm{~min}$. The data at every $20 \mathrm{~min}$ have been averaged and those correspond to 10:10 LT represent the averaged values for the time bin 10:00-10:20 and 10:30 LT represents the values for 10:20-10:40 and so on. The temporal variation of the EIA are obtained by using the TEC data from the aforesaid stations. Presented here in Fig. 1 is an example for the evolution of the EIA on a typical day. Such plots for different days have been used to obtain the EIA parameters like TEC at the northern crest (C), TEC at the trough (T) and location of crest in Magnetic latitude (Mlat). As the measurement of TEC in the southern latitudes are not possible from this longitude sector, the TEC minima observed over the dip equatorial station is assumed as the trough value, which is further confirmed using measurements from the Planar Langmuir Probe (PLP) on board the CHAllanging Minisatellite Payload (CHAMP). The strength of EIA has been estimated using the relation $[(\mathrm{C}-\mathrm{T}) / \mathrm{T}] \times$ Mlat.

The IEEJ is inferred by adding the magnetic field data at the surface at every $20 \mathrm{~min}$ starting from 07:00 LT till the peak of the EEJ. These EEJ values at every $20 \mathrm{~min}$ are correlated with EIA parameters by suitably time shifting the values. The time delay at which the maximum correlation obtained is taken as the response time of the equatorial ionosphere, which means the time taken by the EIA to respond to the changes in the primary zonal electric field. For the present study, the data for March, July and October, which represents both the equinoctial and solstitial months of the solar minimum year 2006 have been used.

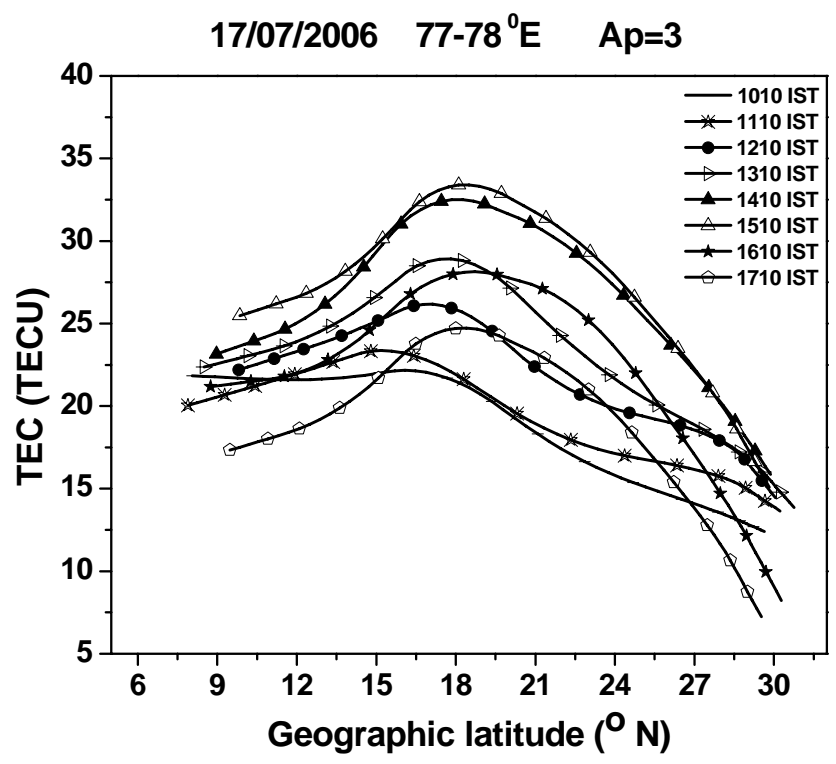

Fig. 1. The evolution of EIA at every $1 \mathrm{~h}$ interval for a typical quiet day obtained from six GPS stations along $77-78^{\circ}$ E longitudes.

\section{Results and discussion}

The scatter plots between the EIA parameters and IEEJ for the months March, July and October of the year 2006 are shown in Fig. 2. The maximum correlations obtained and the corresponding time delays are also shown in each panel. The top panels show the correlation between EIA crest and IEEJ for the aforesaid months. The middle and bottom panels depict the correlation between Mlat of the EIA crest \& IEEJ and EIA strength \& IEEJ, respectively. It is seen that the TEC at crest $(C)$ shows very high correlation $(R>0.90)$ with IEEJ for all the three months. Correlation between Mlat and EIA strength shows strong seasonal dependence with maximum correlation during March and minimum in October. In order to highlight the dependence of correlation on time delays shown in Fig. 3 are the variation of correlation coefficient obtained for the EIA parameters and the time delays for the considered months of study. For all EIA parameters, correlation first increases, reaches a maximum and then decreases as the time delay increases. It is found that the response time shows significant month-to-month variation. The TEC at crest shows very good correlation for all seasons and the time delay is found to be maximum during the summer month. Time delay for the other two parameters is also maximum during the summer month. One possible reason for this relation might be due to presence of strong equatorward wind in the Northern Hemisphere during the summer. The wind can retard the ionization from diffusing along the geomagnetic field lines, which will be reflected in TEC at crest and Mlat of EIA. The correlations are very high during March compared to October. The corresponding delays are also found to be smaller during March than 

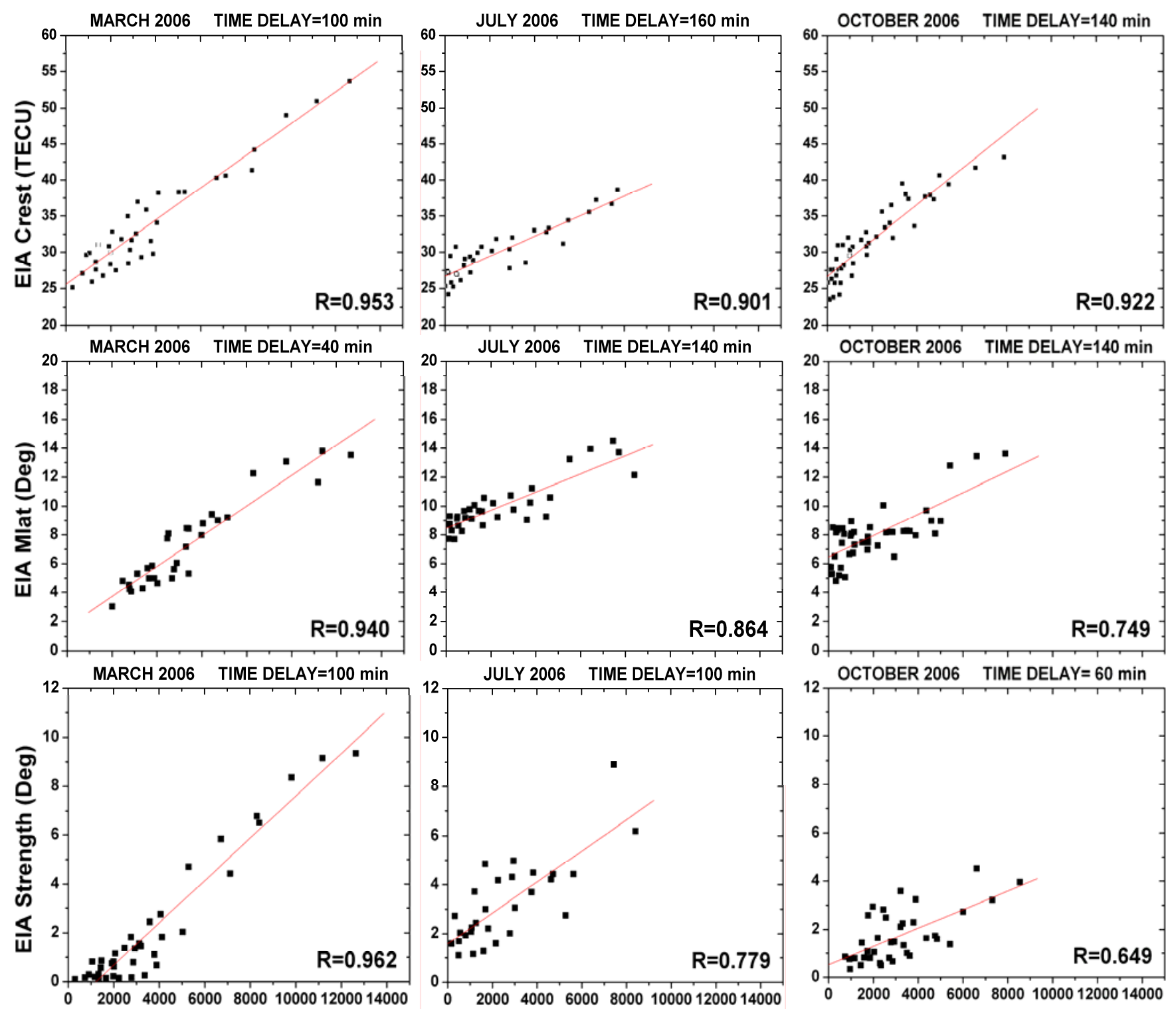

Integrated Electrojet Strength (nT)

Fig. 2. Scatter plots between IEEJ and EIA parameters, showing the maximum correlation for different seasons.

that of October. This difference is believed to be due to the following reason. During the equinoctial months, the uncertainties associated with the wind effects are considerably less over the equatorial ionosphere. However, the recent studies from Trivandrum show that there exists significant asymmetry in the strength of the meridional winds in both equinoxes (G. Manju, Space physics Laboratory, Trivandrum, personal communication). The time delay in Mlat shows a minimum of 40 min during the month of March. This indicates that the field aligned diffusion of plasma and hence the evolution of EIA would be faster when the wind effects are negligible. Similarly, the strength of the EIA also shows considerable changes with season. The TEC at trough (T) is the only additional parameter that goes in to the calculation of the EIA strength. This parameter further depends on the strength of the electric field and exhibits strong seasonal variability. This is well evident from the mean EEJ values estimated for the considered days during the months March, July and October as shown in Fig. 4. As expected, the EEJ shows maximum values during March and October and a minimum in July. Naturally, one would expect maximum correlation between the EEJ and EIA during March and October and a minimum in July. Contrary to this, our results show a maximum correlation in March and a minimum correlation in July and 
Table 1. The observed time delay and linear regression coefficients corresponding to maximum correlation obtained between EIA parameters (Crest TEC and Mlat) and IEEJ for different months.

\begin{tabular}{lccccc}
\hline Month and year & EIA parameter & Time delay (in min) & Slope $(M)$ & Intercept $(C)$ & SD \\
\hline \multirow{2}{*}{ March 2006 } & Crest & 100 & $2.22 \times 10^{-3}$ & 25.58 & 2.14 \\
& Mlat & 40 & $1.05 \times 10^{-3}$ & 1.62 & 1.05 \\
\hline \multirow{2}{*}{ July 2006 } & Crest & 160 & $1.38 \times 10^{-3}$ & 26.69 & 1.60 \\
& Mlat & 140 & $6.26 \times 10^{-4}$ & 8.46 & 0.90 \\
\hline \multirow{2}{*}{ October 2006 } & Crest & 140 & $2.48 \times 10^{-3}$ & 26.66 & 1.99 \\
& Mlat & 140 & $7.42 \times 10^{-4}$ & 6.48 & 1.26 \\
\hline \multirow{2}{*}{ October 2005 } & Crest & 140 & $1.11 \times 10^{-3}$ & 32.37 & 3.93 \\
& Mlat & 60 & $4.03 \times 10^{-4}$ & 5.78 & 1.72 \\
\hline
\end{tabular}

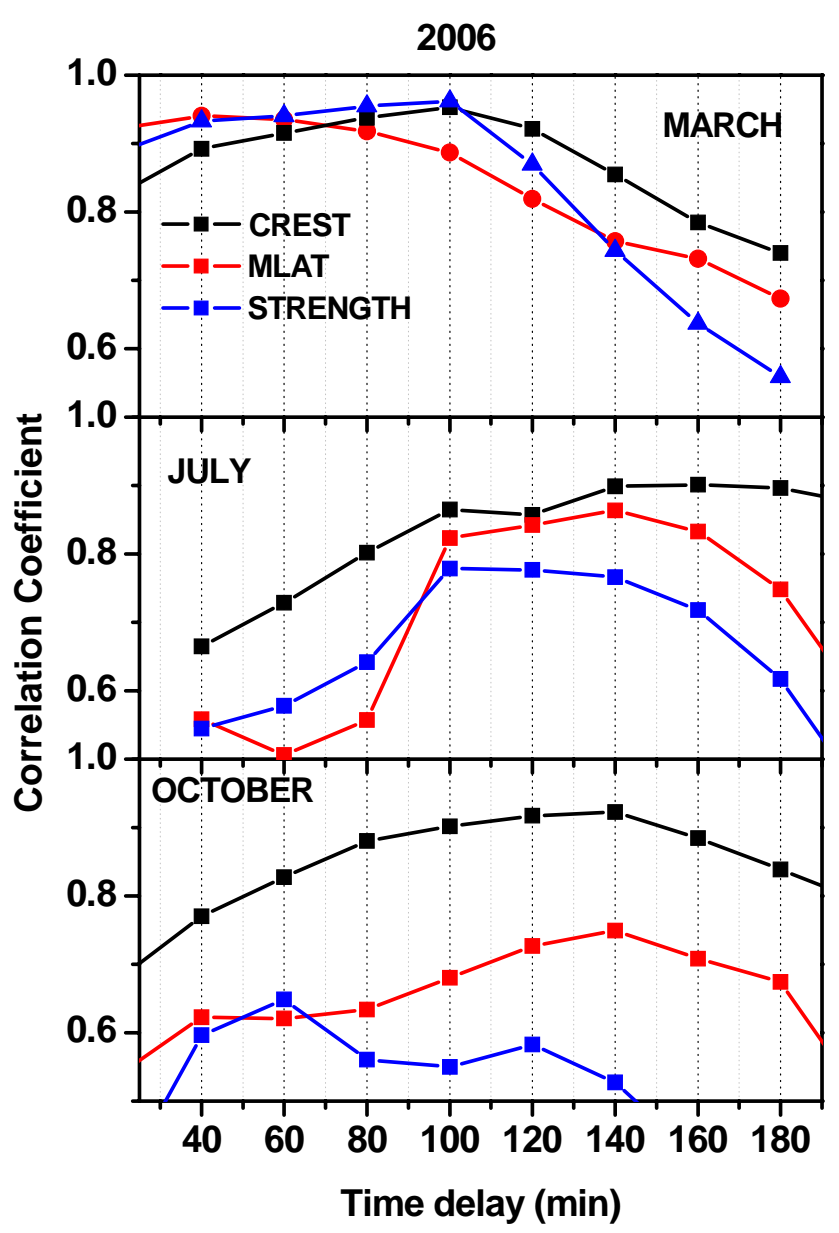

Fig. 3. Correlation between IEEJ and EIA parameters for different time delays.

October. A possible reason for this could be the role played by thermospheric winds whose effect is to spread the electron density at the EIA crest region, depending upon the direction

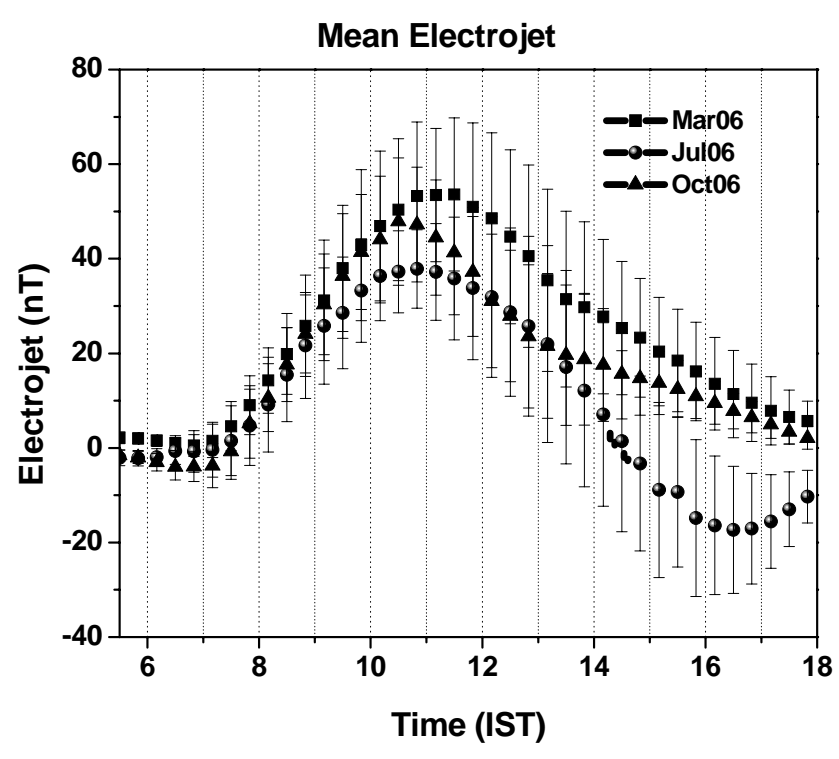

Fig. 4. Mean EEJ induced magnetic filed at surface for the March, July and October months of year 2006.

and strength of the wind. However, since we do not have an estimate on thermospheric winds, the proposed mechanism cannot be substantiated at this moment.

Once the response time, or the time delay at which maximum correlation is determined for a given season, from the regression lines, the coefficients relating TEC and IEEJ can be obtained. Using these coefficients, it is possible to have a "near-real time prediction" of the TEC at EIA crest and location of EIA crest using a linear relationship $\mathrm{TEC}_{(\mathrm{P})}=M \cdot \mathrm{IEEJ}+\mathrm{C}$, where, $\mathrm{TEC}_{(\mathrm{P})}$ is the predicted TEC, $M$ is the slope and $\mathrm{C}$ is the $\mathrm{Y}$-intercept, which are obtained as described earlier. Table 1 shows the observed time delays and corresponding values of $M, \mathrm{C}$ and the standard deviation (SD) obtained from maximum correlation plots for different months. Using these coefficients and the prior knowledge of 

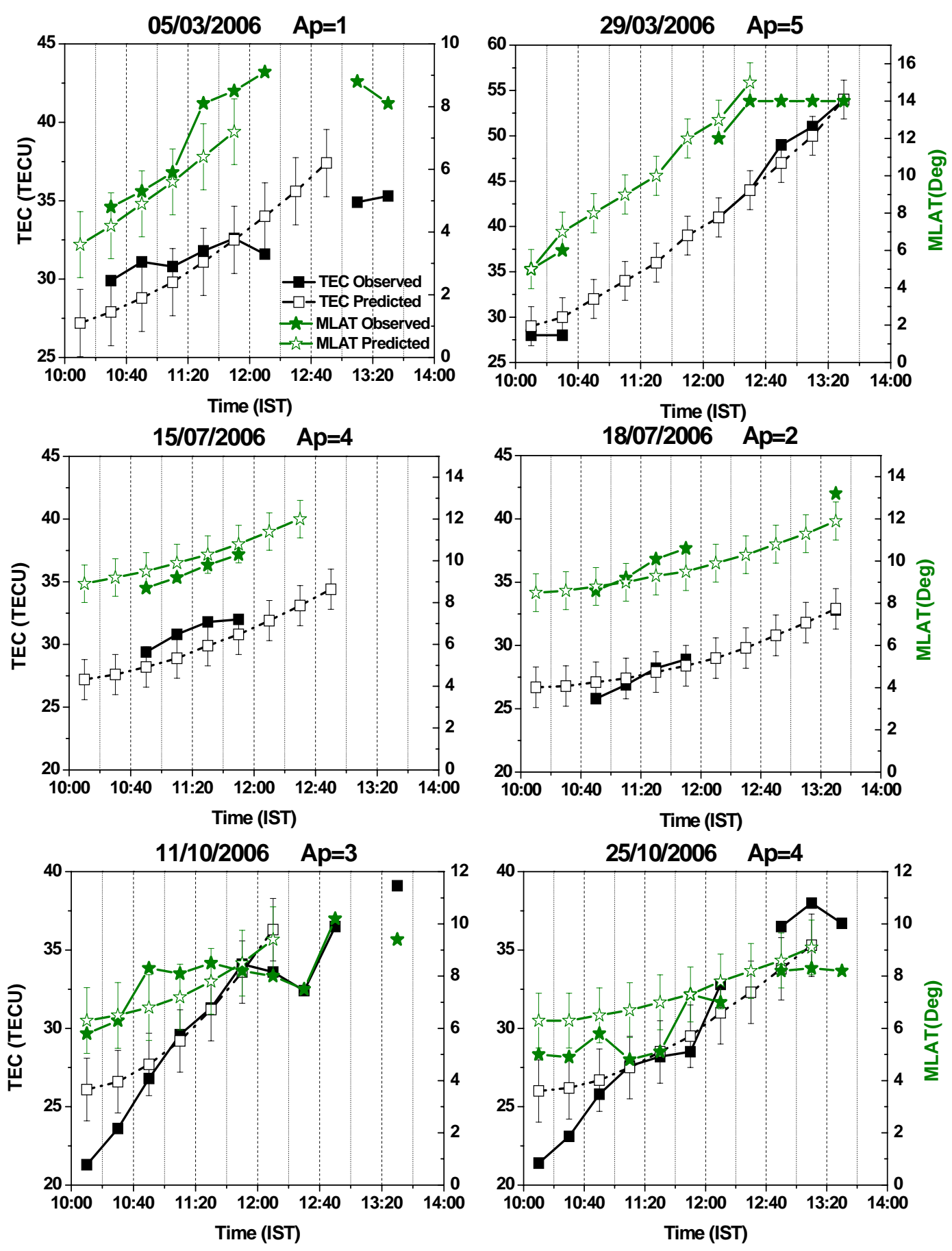

Fig. 5. The predicted and observed values of TEC at the crest and magnetic latitude of crest for different days on March, July and October for the year 2006 .

the plausible time delays we have attempted the prediction of the time evolution of the TEC at EIA crest and its location for different days. The result of the sample "prediction" for different days during March, July and October months are shown in Fig. 5. The filled symbols represent the measured values and open symbols the predicted ones. Only quiet days of Ap values $<10$ are considered for this study. There are some gaps in the data points since we used the data at higher elevation angles $\left(>60^{\circ}\right)$ for the present analysis. Fairly good match has been seen between predicted and observed values. However, deviations are also seen on some occasions. The observed deviation is believed to be due to the role played by 

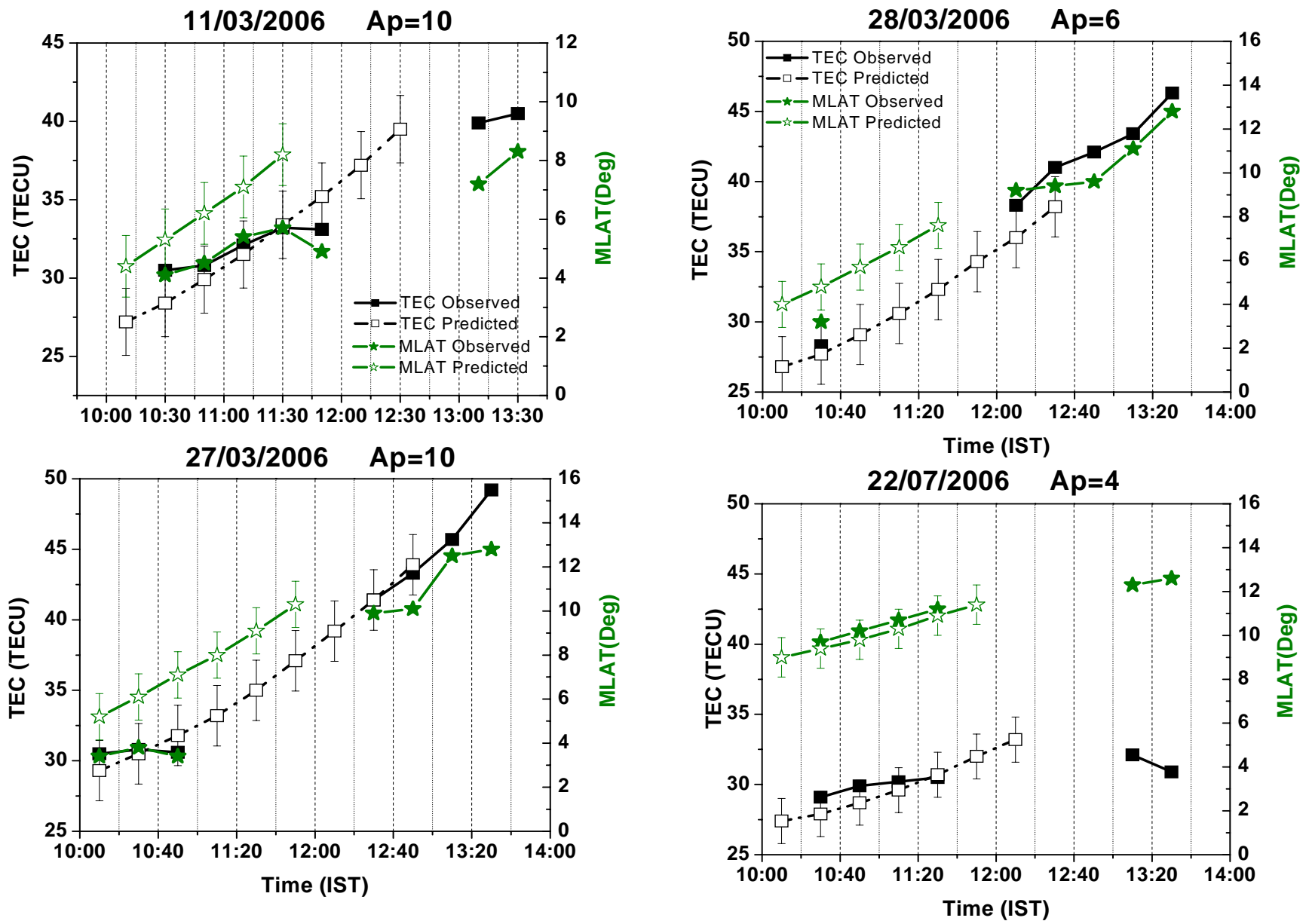

Fig. 6. Same as Fig. 5 but for two moderately disturbed days during March 2006.

the horizontal winds in the day-to-day evolution of the EIA. However at present we do not have any means to delineate their individual effects.

In order to check the validity of the prediction on disturbed conditions, the analysis has been extended further to the disturbed days. These days were not included in the calculation of the model coefficients. Figure 6 shows the observed and predicted values for two slightly disturbed days $(A p=10)$. It is found that Mlat is more affected by the geomagnetic activity than the TEC at crest. This indicates the influence of thermospheric winds (here it can be disturbance induced) on the day-to-day variability of EIA. Nevertheless, the prediction could be successfully used even for moderately disturbed periods.

It must be mentioned here that the quiet days chosen for the prediction shown above (Fig. 5) were also included in the database for determining the correlations. Hence, another attempt has also been made to predict the EIA parameters on some other period, which falls under the same season, which are not included for the time delay analysis. For this, we chose few days from March and July 2006 (which was not

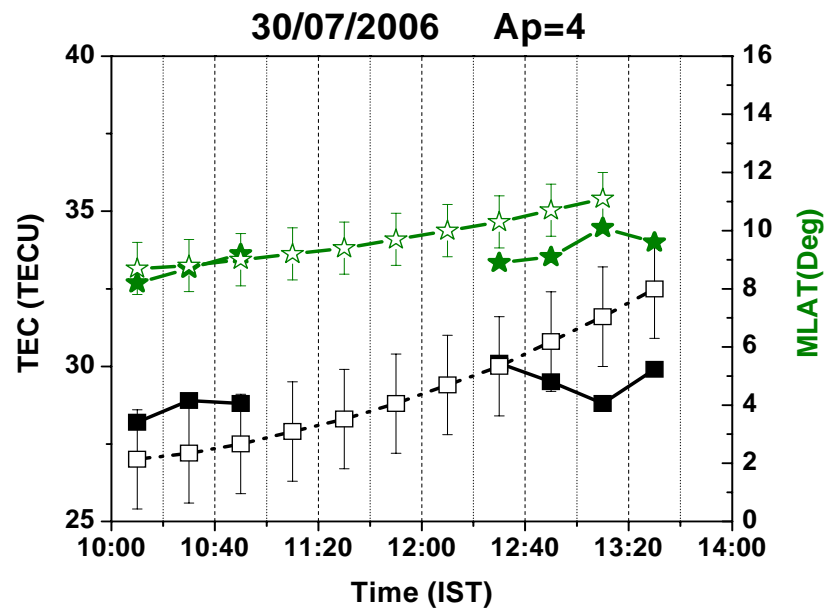

Fig. 7. Same as Fig. 5 but for those days, which are not gone in to the time delay analysis.

used for the coefficient estimation) and October 2005, and the coefficients from the model corresponding to the same season are used for "predictions". The result is depicted in Figs. 7 and 8. It is clear from the figure that the prediction holds good for these days as well. Unfortunately, analysis of days corresponding to other seasons is not possible at the 

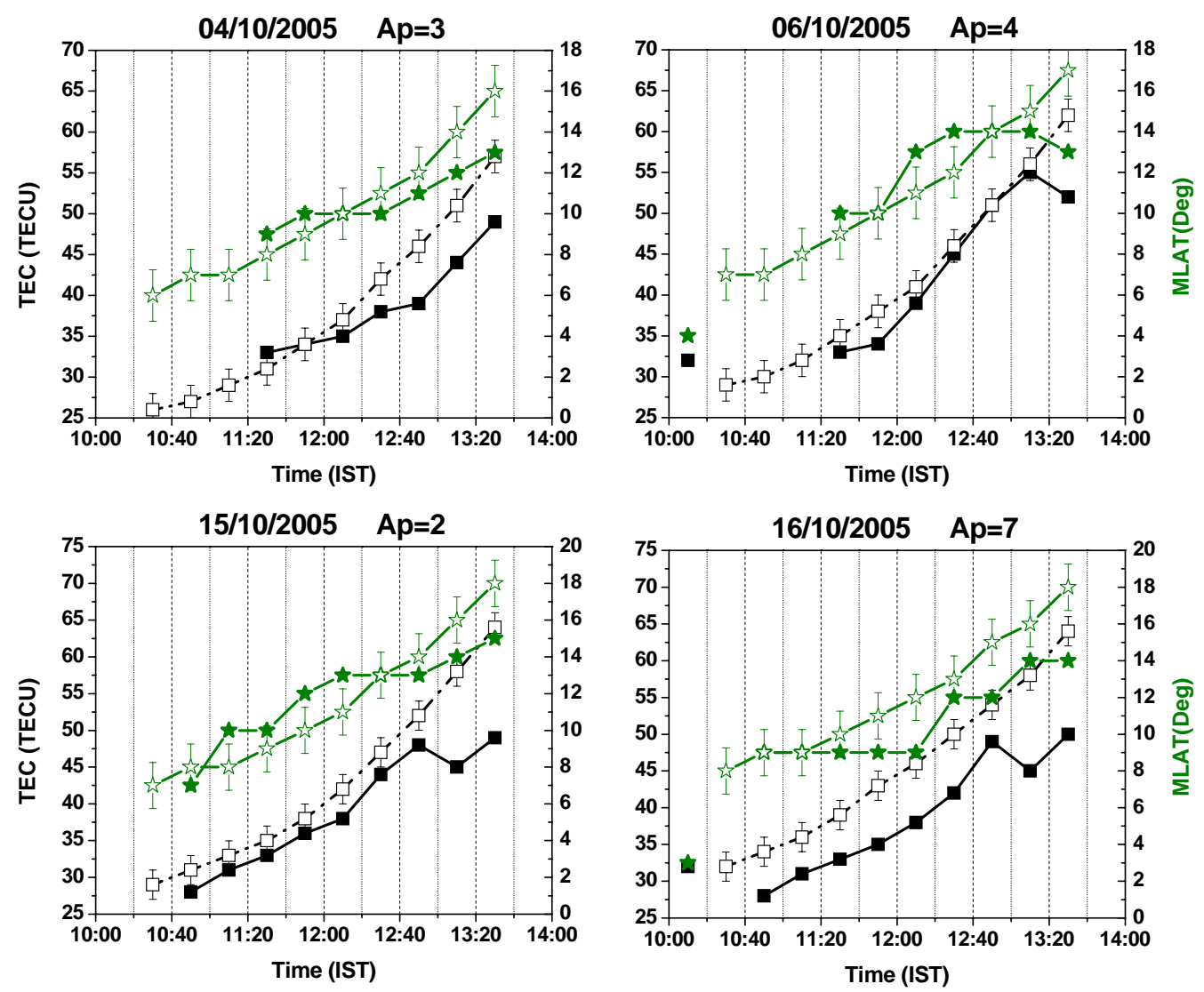

Fig. 8. Same as Fig. 5 but for few days in 2005 , which are not gone in to the time delay analysis.

moment because of the unavailability of data. At this stage, the model can only be used for this longitude sector and for low solar activity, since there are no additional terms in the model equations to include the longitudinal variations of solar flux changes (which determines the conductivities to a large extent) etc. Incorporating these parameters would further improve the predictions. The correlation analysis was performed on the data corresponding to October 2005, and the coefficients were determined (shown in Table 1). It is important to note that the coefficients thus obtained in the year 2005 are consistent with those obtained using the data corresponding to the year 2006, which is also revealed by the fairly good predictions obtained.

On the whole, the present study has a high scope of practical application for the near-real time ionospheric predictions, which are required for GAGAN like navigational systems. As we can track the evolution of EIA prior to its maximizing time, we will have an idea about the location and the TEC value at the crest. This can alleviate the risks involved in finding the exact position within the equatorial/low latitude region where very high gradients in electron density exists. However, this study is a preliminary attempts towards the ultimate prediction of the evolution of EIA and more analysis involving long term data set, has been called for in future.

\section{Conclusions}

Correlation between EEJ and EIA has been verified using TEC data obtained from six GPS TEC receiver stations along the Indian longitudes for different months of the year 2006. EIA parameters like the strength of the EIA, TEC at the crest and location of crest showed a good correlation with integrated EEJ strength. There exists a characteristic time delay between the EEJ and EIA parameters, which vary with season. The time delay corresponds to the maximum correlation is regarded as response time of equatorial ionosphere. The seasonal variation observed in the time delay is suggested to be due to the changes in EEJ strength and seasonal variations in the pattern of thermospheric winds. Using the response time and liner relationship between these two processes a near-real time prediction of EIA parameters has been attempted, which showed good results even during moderately disturbed periods.

Acknowledgements. This work was supported by Department of Space, Government of India. One of the authors, Lijo Jose, gratefully acknowledges the financial assistance provided by the Indian Space Research Organization through the research fellowship.

Topical Editor P.-L. Blelly thanks two anonymous referees for their help in evaluating this paper. 


\section{References}

Abdu, M. A., Walker, G. O., Reddy, B. M., Sobral, J. H. A., Fejer, B. G., Kikuchi, T., Trivedi, N. B., and Szuszczewicz, E. P: Electric field versus neutral wind control of the equatorial anomaly under quiet and disturbed condition: A global perspective from SUNDIAL 86, Ann. Geophys., 8, 419-430, 1990.

Anderson, D. N.: A theoretical study of the ionospheric F-region equatorial anomaly I., Planet. Space Sci., 21, 409-419, 1973a.

Anderson, D. N.: A theoretical study of the ionospheric F-region equatorial anomaly II. Results in the American and Asian sectors, Planet. Space Sci., 21, 421-442, 1973b.

Appleton, E. V.: Two anomalies in the ionosphere, Nature, 157, 691-693, 1946.

Balan, N. and Iyer, K. N.: Equatorial anomaly in ionospheric electron content and its relation to dynamo currents, J. Geophys. Res., 88, 10259-10262, 1983.

Deshpande, M. R., Rastogi, R. G., Vats, H. O., Klobuchar, J. A., Sethia, G., Jain, A. R., Subbarao, B. S., Patwari, V. M., Janve, A. V., Rai, R. K., Singh, Malkiat, Gurm, H. S., and Murthy, B. S: Effect of electrojet on the TEC of the ionosphere over India subcontinent, Nature, 267, 599-600, 1977.

Dunford, E.: The relationship between the ionospheric equatorial anomaly and the E-region current system, J. Atmos. Terr. Phys., 29, 1489-1498, 1967.

Forbes, J. M.: The equatorial electrojet, Rev. Geophys. Space Phys., 19, 469-504, 1981.

Huang, Y.-N., Cheng, K., and Chen, S.-W.: On the equatorial anomalyof the ionospheric total electron content near the Northern Anomaly Crest Region, J. Geophys. Res., 94, 515-525, 1989.

Klobuchar, J. A.: Ionospheric Effects on GPS, vol. 2, Progress in Astronautics and Aeronautics, 1996.
Martyn, D. F.: Atmospheric tides in the ionosphere - I. Solar tides in the F2 region, Proc. Roy. Soc. London A, 189, 241-260, 1947.

Mitra, S. K.: Geomagnetic control of region F2 of the ionosphere, Nature, 158, 668-669, 1946.

Raghavarao, R., Sharma, P., and Sivaraman, M. R.: Correlation of ionization anomaly with the intensity of electrojet, Space Res., 18, 277-280, 1978.

Rama Rao, P. V. S., Gopi Krishna, S., Niranjan, K., and Prasad, D. S. V. V. D.: Temporal and spatial variations in TEC using simultaneous measurements from the Indian GPS network of receivers during the low solar activity period of 2004-2005, Ann. Geophys., 24, 3279-3292, doi:10.5194/angeo-24-3279-2006, 2006.

Rastogi, R. G.: The Diurnal Development of the Anomalous Equatorial Belt in the F2 Region of the Ionosphere, J. Geophys. Res., 64, 727-732, 1959.

Rastogi, R. G. and Klobuchar, J. A.: Ionospheric electron content within the equatorial F2 layer anomaly belt, J. Geophys. Res., 95, 045-052, 1990.

Rastogi, R. G. and Rajaram, G.: Electrojet effects on the equatorial F-region during magnetically quiet and disturbed days, Ind. J. Pure Appl. Phys., 9, 531-536, 1971.

Reddy, C. A.: The equatorial electrojet, Pageoph., 131, 485-508, 1989.

Richmond, A. D.: Modeling the ionospheric wind dynamo: A review, Pageoph., 131, 413-435, 1989.

Rush, C. M. and Richmond, A. D.: The relationship between the structure of the equatorial anomaly and the strength of the equatorial electrojet, J. Atmos. Terr. Phys., 35, 1171-1180, 1973.

Sastri, J. H.: The relationship between the structure of the equatorial anomaly and the strength of the equatorial electrojet, Ind. J. Radio Space Phys., 19, 225-240, 1990.

Stolle, C., Manoj, C., Lühr, H., Maus, S., and Alken, P.: Estimating the daytime Equatorial Ionization Anomaly strength from electric field proxies, J. Geophys. Res., 113, A09310, doi:10.1029/2007JA012781, 2008. 